\title{
Perceptions of students' on the Use of WhatsApp in Teaching Methods of English as Second Language at the University of Namibia
}

\author{
Nchindo Richardson Mbukusa ${ }^{1, *}$ \\ ${ }^{1}$ Faculty of Education, University of Namibia, Windhoek, Namibia \\ *Correspondence: Faculty of Education, University of Namibia, Windhoek, PO Box 174, Rundu, Namibia. Tel: \\ 264-61-206-3619. E-mail: nmbukusa@unam.na
}

Received: April 6, 2018

Accepted: June 5, 2018 Online Published: November 18, 2018

doi: $10.5430 /$ jct.v7n2p112

URL: https://doi.org/10.5430/jct.v7n2p112

\begin{abstract}
Recently, electronic mobile devices have been widely used for attaining knowledge, asking questions and retrieving information. Mobile devices and their features have been in the glare of publicity for educational purposes. The WhatsApp application instant messaging platform has become the most popular mobile device application regarded as one of the teaching and learning styles that facilitate collaborative learning as students are beaming with own smartphones.

Nowadays, it is challenging to help students raise their interest in learning. Thus WhatsApp presents itself as one of the inventive teaching methods that can attract students and provide them with opportunities for further learning. WhatsApp increases helps students to work smarter and more effectively. This research investigates the students' perceptions towards using the WhatsApp application as a learning tool for Teaching Methods of English as Second Language on a Bachelor's degree programme at the University of Namibia. To achieve this, about 99 students in the same cohort completed the self-administered questionnaires. The study revealed, amongst many, that WhatsApp can impact negatively on the performance of tertiary students, especially those who do not own smartphones. The platform shows a variance on balancing online activities (WhatsApp) and academic preparation, and distracts students from completing their assignments and adhering to their private studies time table. However, students enjoy using WhatsApp as a tool for learning and calls for institutions to offer internet amenities as a top urgency in contemporary instruction.
\end{abstract}

Keywords: WhatsApp, mobile learning, teaching and learning platform, English second language

\section{Brief overview of the study}

\subsection{The Existence of WhatsApp and Its Usage}

According to Sharples, Taylor \& Vavoula (2007) mobile phones have widely been used as a tool for learning as it grants both educators and students with opportunities for inventive instruction. Additionally, its characteristic of enabling students to participate in lessons and access material, as well as the teacher, outside class hours, at any place and any time, makes mobile learning (m-learning) less obstructive than other forms of technology-enabled learning (Laurillard, 2007; Beger \& Sinha, 2012). Uys et al (2012) also assert that undergraduates spend a weighty amount of time on social networking sites. Ho (2011), states that WhatsApp ("WhatsApp Messenger,") is a free synchronous messaging application that can be used to send and receive instant messages amid individuals and in groups. WhatsApp is a cross-platform application that works mainly on smartphones and Android tablets.

Students can communicate with their lecturers and other students in real time with the availability of Wi-Fi connections and mobile data as it is much cheaper to communicate via social networking sites. This habit has resulted in partial use of phone calls or Short Message Service (SMS's). Social networking and social media applications such as Facebook, WhatsApp, Line, Twitter, WeChat, offer the scenarios for extending learning beyond the classroom. WhatsApp, via smartphones can advance communication skills as students discuss and share information (Echheverria, Claderon, Nussbaum, infant \& bravo, 2011). 


\subsection{Why use WhatsApp in the Teaching Methods of English in the Teaching and Learning Time?}

WhatsApp can cover large numbers of students within a short period of time. Students from the same class can easily have their dialogue on certain topics via this application as it affords immediate response within the group members to join the chat thus making the communication effective (Trentin \& Repetto, 2013). Fogg (2010) asserts that knowledge can be found all over the place, anytime and in numerous arrangements. One such format that can be used is WhatsApp.

WhatsApp is one of the resourceful teaching methods which fascinates students' attention, responsiveness and provides fun-based learning. It allows the students to express their thoughts and ideas via various features of the WhatsApp application platform such as attaching pictures, sharing videos, sharing web-links, recording videos and many more. Students could deliver their responses freely and the teacher responds to students' inquiries and comments, starts new issues, or posts queries (Dunlap, 2006). WhatsApp helps the students to get enthusiastically involved in learning activities via various features on this application.

\subsection{What is Happening in the Classroom and WhatsApp?}

The main reason WhatsApp was explored in this case was that students already used the platform to interact with each other on several topics of their own interest. The lecturers allowed students to use their smartphones in the classroom. Students could record lectures and replay them in their own time for reflective purposes and then post any queries to colleagues. Students from time to time also posted more items of discussion that emanated from the classroom encounters. Students had added the lecturer to their chats with the intention of probing comments from them. The lecturer just observed their communication and later guided the discussions. From time to time, the lecturer would post items for discussion on the platform.

Following the learning styles of Kolb (1984) where students can learn through assimilation (watching and thinking), diverging (feeling and watching), accommodating (doing and feeling) and converging (doing and thinking), the lecturers decided to engage students via WhatsApp and see how they could react with extended learning. A good number of students in the classroom and those on distance learning platforms were invited and they decided to join (Church \& Oliviera, 2013 and Bere, 2013). Students socialised and freely transferred and shared information, ideas, pictures and many more that was available online for their own exploration and learning (Vygotsky, 1978; Cohavi, 2013). The lecturer was not highly active and only appeared to direct the discussions. The discussions were not meant for assessment.

\subsection{Problem Statement}

The researchers noted that students face numerous problems in learning English language. Most students earlier expressed that learning in the classroom is boring and makes them feel stressed. For this reason, the researchers tried to find new ways of teaching English that helps students make the process of learning exhilarating and help them continue their learning after they have left the classroom through using their smart phones. In this study, the researchers endeavoured to find out the upshots of using "WhatsApp messenger" in learning Teaching Methods of English Language among university students. Teaching Methods of a second language demands the ability of demonstrating the use of grammar and its related facts accurately and fluently. This is premised on the fact that students have already done syntax, morphology, semantics and lexical development of the language across skills. English Teaching Methods module was selected as it is a demonstration of all facets that have been studied in English Second Language as a teaching major. By their fourth year, students should have already covered the above areas and are ready to demonstrate the fact that they could one day teach the content. Students showed an inclination towards using WhatsApp for their own discussions that were sometimes not geared towards fixed learning. The valuable time spent on such discussions could be used for discussions within the realm of learning and contribute to their grasp of teaching methods.

This study therefore allowed the researchers to understand how social networking applications such as WhatsApp could be used outside and in the classroom and how this might compliment the classroom teaching activities.

The objectives for this study therefore are to:

(a) Identify the use of WhatsApp as a learning tool used by a group of University of Namibia students in Teaching Methods of English as a Second Language classroom.

(b) Identify students' perceptions about the use of WhatsApp in Teaching Methods of English as a Second Language classroom.

(c) Determine whether or not WhatsApp use significantly contributed to the students learning in Teaching Methods of English as a Second Language classroom. 


\section{Literature Review}

Wood (2003) and Zurrita \& Nussbaum (2004) have shown that mobile tools play a significant part in supporting teaching and learning as they underwrite the reduction of the digital gaps in developing countries as mobile phones and personal digital assistants (PDA) are easily accessible and less expensive compared to laptops. Moreover, Metcalf, Milrad, Cheek, Raasch \& Hamilton (2008) observed that mobile phones help to improve students' in-class performance in Science and Mathematics. Correspondingly, this raises questions on its impact on language learning classrooms.

According to O'Malley, Vavoula, Glew, Taylor, \& Sharples (2005) the technical infrastructure for M-Learning gives learners a platform to interact with each other outside a classroom setting, M-Learning uses mobile devices with the use of mobile technology that allow students to learn from any place at any time (Laurillard, 2002). Opportunities for M-Learning using smart phones as a platform has further developed education outside the classroom (Traxler \& Leach, 2006; Tindell \& Bohlander, 2012). Some researchers have showed that using WhatsApp in education via smartphones can be disruptive and a distraction because it can cause students to be disengaged from their physical environment. Although students may be disengaged from their physical environment, smart phones provide the students with the ability to learn outside a classroom environment where the students are the center of learning (Sharples, Taylor \& Vavoula, 2007). With easy and ready availability of mobile phones students tend to spend a lot of time on social networks. They also have the ability to communicate with other students and their lecturer in real time and access to a wide amount of online material.

Attewell (2005) studied the effects of mobile technologies on learning and developed an SMS-based course to stimulate learners to study foreign language through mobile phones. The findings showed that learners achieved a greater development in reading comprehension. In addition, learners' motivation had amplified towards learning and using the target language. Cavus and Ibrahim (2008) investigated the use of wireless technologies in education with specific locus to the possibility of learning new technical English language words using Short Message Service (SMS) text messaging. Results showed that students relished using their mobile phones to learn new words. Rambe and Bere (2013) examined mobile instant messaging to make other circumstances for learners' alliance in relaxed spaces, in response to the very limited lecture contact time and the little students' contribution. Results exposed that WhatsApp positively impacts students' ability to contribute and join with peers online at any time. The roles of the teachers have been transformed to enablers and the learners' roles have changed to originators, collaborators and group leaders. Alfaki and Alharthy (2014) studied the influence of using social networks to promote learners' English language. Their results disclosed that learning through social networks was more operative than old-style learning which looked to the classroom as a place of acquiring information. Besides, they discovered that teamwork was a useful learning strategy in improving one's foreign language, and WhatsApp encourages collaboration among students.

Alfattah (2015) conducted a study to determine the effectiveness of using a WhatsApp Messenger as one of mobile learning method to cultivate students' writing skills. Cakir, (2015) explored the current use of mobile phones in a foreign language teaching from the prospective teachers' opinions and attitudes on exploiting the mobile phone as an instructional tool for foreign language learning purposes in the educational and instructional setting of foreign language teaching classrooms. Results showed that most of the participants liked to use their mobiles as instructional tools to help them in learning English. The results also gave some insights as to how foreign language teachers could employ suitable approaches to make the process of learning and teaching English meaningful and communicative. They suggested that the participants would like to make use of mobile phones for educational purposes when they become teachers of English.

\section{Methodology}

This study used a descriptive quantitative research approach, with focus on a survey in order to provide an efficient experiential investigation. Generally, a survey is employed to gather data from samples to know and describe the characteristics or criteria that include amongst many, perceptions, behaviour, attitudes, belief and opinions of the population.

The research was conducted during the 2016/2017 cohorts of the UNAM Academic Calendars. The reason for the choice is that the researchers worked with the cohorts and could easily get a high rate of responses. The cost involved was also low. Respondents were required to circle their answers according to the scale of $1-5$ ( $5=$ Strongly Agree, $4=$ Agree, 3 = Undecided, 2 = Disagree, $1=$ Strongly Disagree). A total of 99 using WhatsApp respondents participated willingly. 
Prior to distributing the questionnaire, the researchers had created a WhatsApp group for the respondents according to their TME groupings. These groupings used to communicate with the respondents outside classroom. The researchers posted a large variety of materials for students to read and use for their interactions. The choice of activities and tasks posted and the results of the candidates were not a matter of interest in this study.

Generally, respondents would post anything, including their choices from the activities done in the class or would bring their own topics for discussion but restricted to TME. Students were also encouraged to find any relevant learning materials and post on the platform for extended discussions.

Conbach's alpha measure was used in this study as an instrument to measure the results of the survey. Cronbach's alpha measures internal consistency, that is, how closely related a set of items are as a group. It is considered to be a measure of a scale reliability.

\section{Results}

\subsection{Effectiveness of WhatsApp in Teaching and Learning of the English Language ( $n=99)$}

Figure 1 below depicts the effectiveness of WhatsApp as a teaching and learning method for the English language. For this study, the acceptable levels of attitudes, behaviour and utility of WhatsApp were set at $60 \%$. All the 99 student teachers (100\%) for the English language Course that were completing the third year of study, completed the questionnaire. The completeness rates of the questionnaire items were highest with shorter items that is behavioral $(99 \%-98 / 99$, items $=3)$; utility $(87.7-87 / 99$, items $=8)$ and attitudes $(85.9 \%-85 / 99$, items $=13)$. The overall students' impression of effectiveness of WhatsApp as a Teaching and Learning Methodology for the English language was very high $(80.5 \%)$. More than 8 out of 10 student teachers had a good attitude and positive behaviour towards the use of WhatsApp as a teaching learning method for the English language. However, over a third of the students responded that they may have not optimally utilized WhatsApp as a teaching and learning tool for the English language (Figure 1).

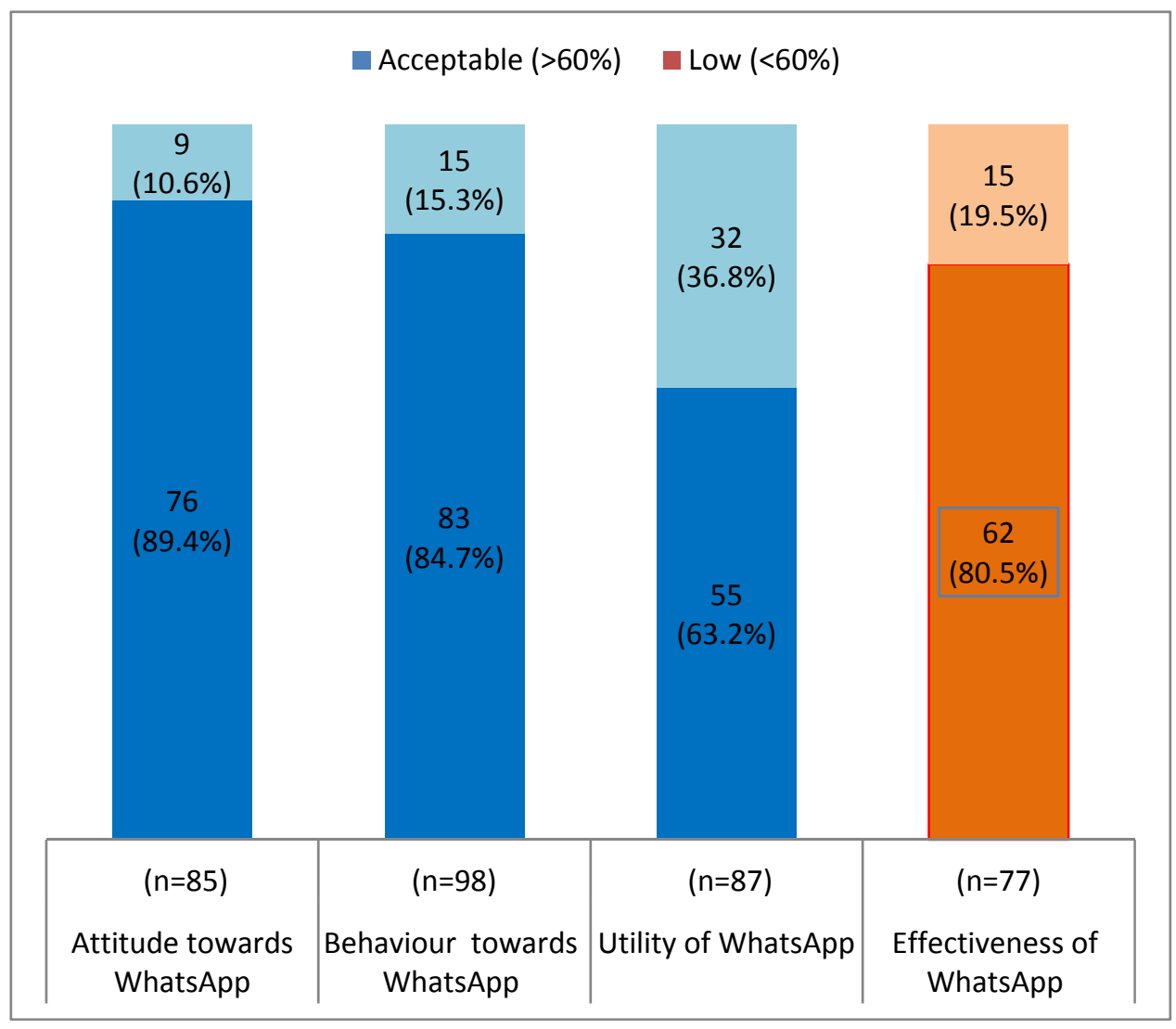

Figure 1. Attitudes, Behaviors, Utility and Students' Impressions Effectiveness of WhatsApp in English Leaning 


\section{Level of attitude, utility, behaviour towards WhatsApp in English (99)}

Figure 2 below displays histograms showing the distribution of the study respondents by the level of attitudes, behaviour and utility of WhatsApp as a TLM for the English language. The levels for each respondent were determined as a percentage of the mean score from the respective constructs - that is attitude (mean was out of total score for the items 1-13, utility mean from item 14-21, and behaviour mean from item 22-24). The mean for the three constructs - attitude, behaviour and utilization were 76.1 $\pm 13.3,75.6 \pm 16.6$ and $66.0 \pm 19.2$ respectively (Figure 2a, 2b and 2c). The overall effectiveness of the WhatsApp in the English language learning had a mean of $72.9 \pm 13.7$ (Figure 2d).

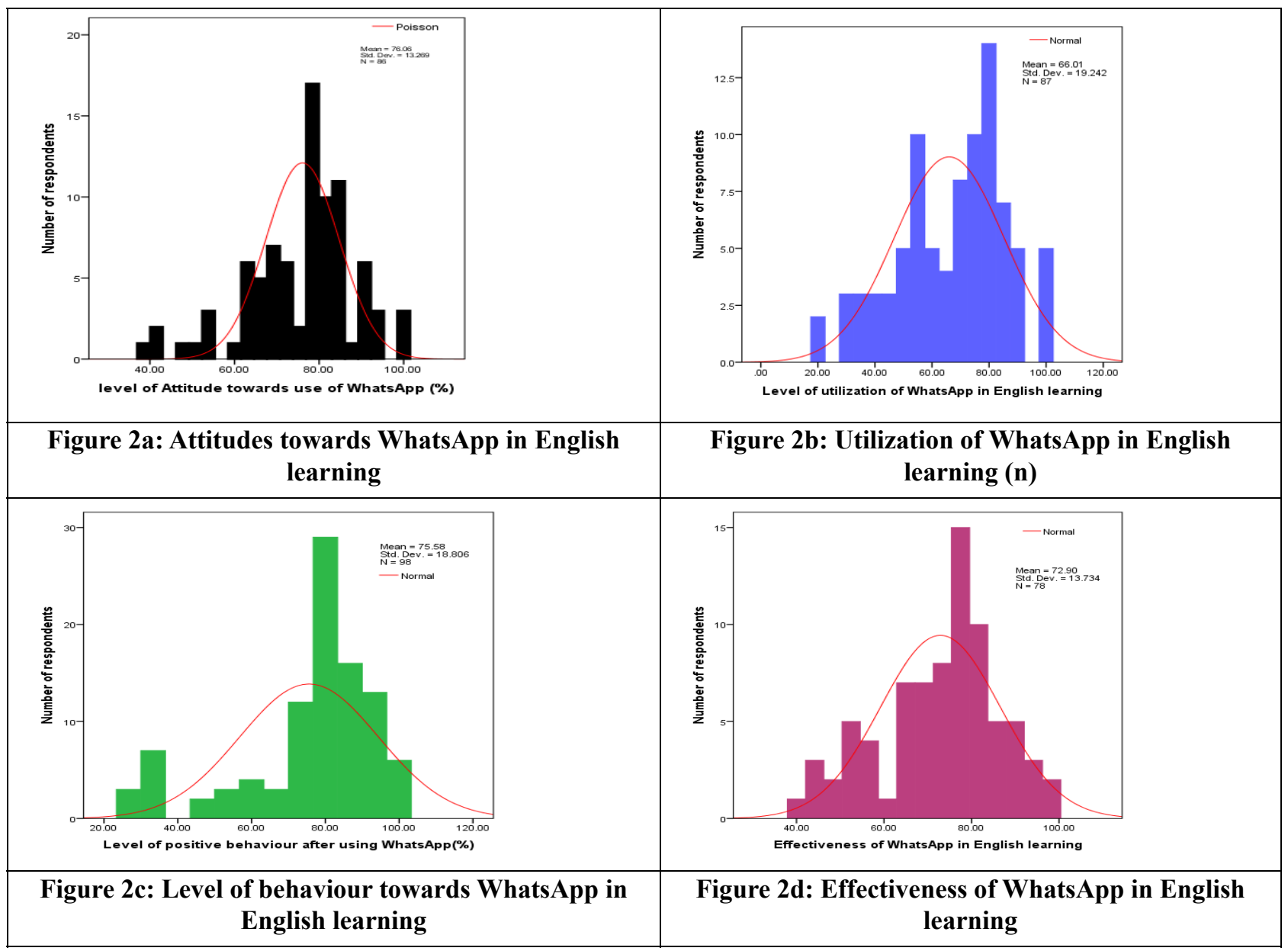

Figure 2. Distribution of Respondents by Level of Attitudes, Utility and Behaviour Towards WhatsApp

\section{Reliability and Validity of Mbukusa-Scale to assess effectiveness of WhatsApp in English learning}

The reliability was determined using Cronbach alpha $(\alpha)$ to determine the internal consistency between the 24-items used on the scale in assessing the effectiveness of the effectiveness of WhatsApp in the teaching and learning of English language. Table 1 shows that the 24- items had a very high level of internal consistence with adjusted Cronbach $\alpha=0.917$. The three constructs attitude (13 items), utility ( 8 items) and behaviour ( 3 items) also showed a high internal consistence with respective adjusted Cronbach alpha measures of $0.845,0.893$, and 0.815 . The principal component analysis (PCA) was used to determine the validity of the questionnaire items in assessing the three constructs - attitudes, behaviour and utility for English learning using WhatsApp. The forced three factor analysis was significant for attitudes, behaviour and utility of WhatsApp (Table 1, Figure 3). 
Table 1. Structure Matrix for the Factor Analysis of the 24-Item Scale for Attitudes, Utility and Behaviour

\begin{tabular}{lllllll}
\hline Item & \multicolumn{2}{l}{ Component } & & & \\
\cline { 2 - 7 } & 1 & 2 & 3 & 4 & 5 & 6 \\
\hline 1. learning was pleasant & .569 & -.245 & .242 & -.015 & .831 & -.114 \\
2. Was a positive idea & .321 & -.194 & .404 & -.203 & .737 & -.012 \\
3. Was easy & .187 & -.094 & .071 & .135 & .875 & -.071 \\
4. Faster knowledge sharing & .569 & -.184 & .532 & .407 & .447 & .123 \\
5. Favours fast smart phone users & .533 & -.490 & .332 & .020 & .530 & .092 \\
6. Helps pass information discussed & .393 & -.285 & .687 & .540 & .210 & .015 \\
7. Messaging was clear & .253 & -.296 & .881 & -.044 & .207 & -.131 \\
8. Intentions understood by people & .166 & -.383 & .830 & .073 & .140 & .071 \\
9. Valuable information communicated & .363 & -.220 & .782 & .176 & .213 & -.349 \\
10. Encouraged peer learning & .406 & -.348 & .412 & .673 & .127 & -.400 \\
11. Lecturer involvement & .025 & .142 & -.069 & .684 & -.072 & .172 \\
12. engage peers and lecturers any time & .359 & -.505 & .336 & .613 & .280 & -.412 \\
13. Continue using WhatsApp & .746 & -.445 & .403 & .156 & .405 & -.093 \\
14. Useful in my teaching methods & .625 & -.277 & .261 & -.016 & .581 & -.415 \\
15. Language productivity improved & .142 & -.845 & .360 & .066 & .180 & -.254 \\
16. Thinking skills improved & .269 & -.847 & .213 & .151 & .108 & -.121 \\
17. Performance improved & .277 & -.851 & .367 & -.048 & .282 & -.312 \\
18. Peer relation improved & .425 & -.785 & .386 & -.046 & .129 & -.135 \\
19. active designing language activities & .452 & -.578 & .310 & -.134 & .183 & -.606 \\
20. Increased confidence & .451 & -.750 & .220 & .192 & .243 & -.543 \\
21. Prepared me to be an active teacher & .140 & -.672 & .288 & .173 & .344 & -.645 \\
22. Use WhatsApp in learning English & .836 & -.352 & .297 & .275 & .495 & -.149 \\
23. I will not stop using WhatsApp & .851 & -.208 & .262 & .199 & .216 & -.088 \\
24. I love WhatsApp & .527 & -.491 & .249 & .289 & .580 & .157 \\
Extraction Method: Principal Component Analysis. & & & & & \\
Rotation Method: Oblimin with Kaiser Normalization. & & & & & & \\
\hline
\end{tabular}

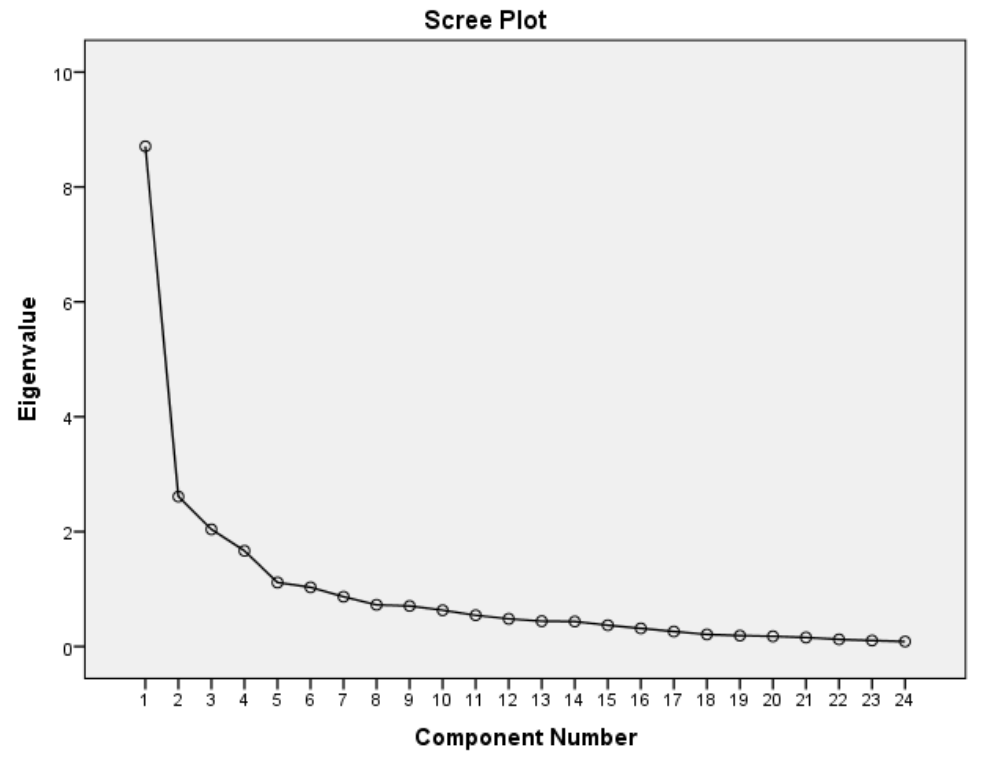

Figure 3. Scree Plot of the 24-item Scale for Attitudes, Utility and Behavior 
Figure 3 shows that 24 items and different constructs were posted for students to share their perceptions towards the use of WhatsApp as a tool to learn and later in their careers also use it for teaching English as a Second Language. The third objective of the study required students to share the effectiveness of WhatsApp in teaching and learning. Figure 3 shows the responses of students. The results show that the covariance of the items approached infinity on the scale. There is a correlation. In other words, the higher the co-efficiency in this survey, the more items have shared covariance and probably measure the same underlying constructs.

\section{Discussion}

It is possible that items used to measure attitudes and behaviour could be irrelevant, off target and even invalid for the study. Using the Cronbach instrument to measure the reliability and validity of the instrument and its constructs, the figures used summaries the responses of the students. It is seen in this figure that all the items passed the minimum requirement in the use of the Cronbach. Such a situation illustrates that questions were relevant, thus helping researchers understand that it was worth extrapolating more meaning from the instrument used. As seen in students' responses in figure 1, effective use of WhatsApp is good as it stands at $80 \%$. This implies that 2 out 10 students may not have the gadgets to use for WhatsApp activities despite the fact that their attitude and behaviour is highly positive. There could be various factors that bar them from using the devices each time activities are posted.

The item on lecturer involvement also cast some interesting postulations. There are possibilities that had the lecturers kept the grades in involvement and use, the picture could have changed. All students could found ways to obtain necessary gadgets and change the results. It is also possible that some students could have shared their attitudes and behaviour with fear.

\section{Conclusion}

WhatsApp can be one of the resourceful teaching methods to attract students and increase ideal contribution among students' ideas and provides quicker and relaxed communication. WhatsApp as a teaching method can impact negatively on the performance of tertiary students especially those who do not own smartphones. The platform can pose difficulties for students in balancing online activities (WhatsApp) and academic preparation, and distract students from completing their assignments and adhering to their private studies timetable. However, students enjoy using WhatsApp as a tool for learning. it has been concluded in this study that the use of WhatsApp should be encouraged to students and institutions should provide internet facilities as a top priority in contemporary instruction.

\section{References}

Alfattah, S. (2015). The Effectiveness of Using a WhatsApp Messenger as One of Mobile Learning Technique to Develop Students' Writing Skills. Journal of Education and Practice, 6, 32.

Attewell, J. (2005). Mobile technologies and learning: A technology update and m-learning project summary. London: Learning Skills Development Agency.

Bere, A. (2013). Using mobile instant messaging to leverage learner participation and transform pedagogy at a South African University of Technology. British Journal of Educational Technology, 44(4), 544-561. http://dx.doi.org/10.1111/bjet.12057

Berger, G., \& Sinha, A. (2012). South African mobile generation: Study on South African young people on mobiles. New York: UNICEF.

Cakir, I. (2015). Opinions and Attitudes of Prospective Teachers for the Use of Mobile Phones in Foreign Language Learning. Contemporary Educational Technology, 6(3).

Cavus, N., \& Ibrahim, D. (2008). M-Learning: An experiment in using SMS to support learning new English language words. British Journal of Educational Technology, 40(1), 78-91. https://doi.org/10.1111/j.1467-8535.2007.00801.x

Church, K., \& de Oliveira, R. (2013). What's up with WhatsApp? comparing mobile instant messaging behaviors with traditional SMS. In Proceedings of the 15th international conference on Human-computer interaction with mobile devices and services (pp. 352-361). ACM.

Dunlap, J. C. (2006). Using guided reflective journaling activities to capture students' changing perception. TechTrends, 50(6), 20-26. https://doi.org/10.1007/s11528-006-7614-x 
Fogg, P. (2010). The 24-7 professor - what to do when home is just another word for the office. Chronicle of Higher Education, 54(21), B12

Laurillard, D. (2002). Rethinking University Teaching: A Framework for the Effective Use of Learning Technologies, (2nd ed.). London: Routledge Falmer. https://doi.org/10.4324/9780203160329

Laurillard, D. (2007). Pedagogical forms for mobile learning framing research question. In Framing research questions (pp. 153-175).

O'Malley, C., Vavoula, G., Glew, J. P., Taylor, J., \& Sharples, M. (2005). Guidelines for learning/teaching/tutoring in a mobile environment. MOBIlearn (pp. 1-57).

Rambe, P., \& Bere, A. (2013). Using mobile instant messaging to leverage learner participation and transform pedagogy at a South African University of Technology. British Journal of Educational Technology, 44(4), 544-561. https://doi.org/10.1111/bjet.12057

Sharples, M. (2013). Mobile learning: research, practice and challenges. Distance Education in China, 3(5), 5-11.

Sharples, M., Lonsdale P., Meek J., Rudman P.D., Vavoula G.N. (2007). An Evaluation of MyArtSpace: a Mobile Learning Service for School Museum Trips. In A. Norman \& J. Pearce (eds.), Proceedings of 6th Annual Conference on Mobile Learning, mLearn 2007, Melbourne. Melbourne: University of Melbourne, pp. 238-244.

Sharples, M., Taylor, J., \& Vavoula, G. (2006). A Theory of Learning for the Mobile Age. R.Andrews and C. Haythornthwaite. The Sage Handbook of Elearning Research, Sage publications, p221-247.

Traxler, J. (2007). Defining, Discussing and Evaluating Mobile Learning: The moving finger writes and having write. The International Review of Research in Open and Distributed Learning, 8(2). https://doi.org/10.19173/irrodl.v8i2.346

Trentin, G., \& Repetto, M. (2013). Using network and mobile technology to bridge formal and informal learning. Elsevier. http://dx.doi.org/10.1533/9781780633626

Uys, W., Mia, A., Jansen, G.F., Van, H., Der Schyff, Michael Andre Josias, M. A., Khusu, M., Gierdien, M., Leukes, N. A., Faltein, S.,\& Gihwala, T. (2012) Smartphone Application Usage Amongst Students at a South African University [www.ist-africa.org]

Vygotsky, L. S. (1978). Mind in society: The development of higher psychological processes. Cambridge: MA: Harvard University Press. 